\title{
MAFFESOLI, M. ÊTRE POSTMODERNE. 265 PP. PARÍS, 2018: LES ÉDITIONS DU CERF.
}

\author{
Prof. Dr. Eguzki Urteaga ${ }^{1}$ \\ Universidad del País Vasco, España
}

Michel Maffesoli acaba de publicar su última obra titulada Être postmoderne (Ser posmoderno) en la editorial Cerf. Conviene recordar que el autor es catedrático emérito de sociología en la Universidad París Descartes, miembro del Instituto Universitario de Francia, director del Centro de Estudios sobre lo Actual y lo Cotidiano (CEAQ), fundado por Georges Balandier, y dirige igualmente el Centro de Investigación sobre el Imaginario (MSH). Impulsor de las revistas Sociétés y Cahiers européens de l'imaginaire, es miembro del comité científico de varios revistas internacionales, tales como Space and Culture o Sociologia Internationalis. En 1992, ha recibido el Premio Humanidades de la Academia francesa por el libro La transfiguration du politique (1992) y ha sido galardonado por varios doctorados honoris causa por las Universidades de Minhoa, Bucarest, Porto Alegre y México.

El pensamiento de Maffesoli gira en torno al análisis del imaginario (constata los invariantes que estructuran el imaginario contemporáneo, siguiendo la estela de su maestro Gilbert Durand) y de lo cotidiano, la relación entre la estética y la vida social, y realiza una crítica pormenorizada del individualismo moderno poniendo de manifiesto el advenimiento de la sociedad posmoderna caracterizada por el resurgimiento del tribalismo, nomadismo, hedonismo y presentismo. En ese sentido, este sociólogo galo se interroga sobre la relación que mantienen las sociedades contemporáneas con la temporalidad, ya que sus obras intentan comprender nuestro vínculo a la inmediatez. A su vez, la sociología de Maffesoli es descriptiva y no prescriptiva en la medida en que no desarrolla ni una crítica sistemática ni un discurso partidista.

Entre sus obras más relevantes, conviene citar La conquête du présent. Pour une sociologie de la vie quotidienne (1979), La connaissance ordinaire. Précis de sociologie compréhensive (1985), Le temps des tribus (1988), Du nomadisme. Vagabondages initiatiques (1997) o Le rythme de vie. Variation sur l'imaginaire post-moderne (2004).

En el prólogo de la presente obra, Maffesoli constata que "la modernidad es lenta en morir, pero su agonía es ineluctable. Los síntomas más manifiestos están ahí: tribalismo, nomadismo, hedonismo" (p. 9). No en vano, a pesar de la realidad de

\footnotetext{
${ }^{1}$ Departamento de Sociología y Trabajo Social, Facultad de Relaciones Laborales y Trabajo Social. E-mail: eguzki.urteaga@ehu.eus
} 
la posmodernidad, se sigue sin reconocer esta mutación, ya que se prefiere adherir a "las convicciones, las opiniones [y] los prejuicios propios a lo que podemos llamar la 'pubertad intelectual' cuyas raíces deben ser buscadas [en el] siglo XVIII y cuyo apogeo se sitúa en el [siglo] XIX" (pp. 9-10). La realidad es que "la saturación de [1a] civilización [moderna] conlleva ineludiblemente la emergencia de otra manera de vivir en común" (p. 11). Por lo cual, la misión de las ciencias humanas y sociales consiste en "pensar las asunciones que son las nuevas maneras de convivir", lo que exige "purgarse de las convicciones y diversas opiniones" (p. 12).

Implica evitar la militancia, alejándose de cualquier tentación de politización y sistematización del pensamiento, ya que, por una parte, "no se puede hacer sistema sobre la cultura en proceso de elaboración" (p. 11); y, por otra parte, es preciso reconocer que "el único absoluto es el relativismo", en la medida en que se trata de elaborar un pensamiento progresivo (p. 12). No obstante, la posmodernidad sigue siendo un tabú que se está convirtiendo en tótem, sabiendo que el 'tótem es, sencillamente, el cemento, el ethos, es decir la ética básica que estructura toda vida en comunidad" (p. 13).

En el primer capítulo, titulado "Oxímoron", Maffesoli observa que, en Francia en particular, país el que se elaboraron los valores propios de la modernidad, es difícil mencionar la posmodernidad y se prefiere hablar de "segunda modernidad", "modernidad tardía" o "hiper-modernidad", con el objetivo, más o menos consciente, de salvar lo que puede serlo del mito modernista y progresista que se impone al mundo entero a partir del siglo XVIII (pp. 15-16). Pero, "unos indicios, cada vez más numerosos, subrayan (...) la saturación de [semejante] mito" (p. 16). De hecho, la crisis actual es otra forma de nombrar la posmodernidad. Supone reconocer que "un ciclo se termina y otro está en gestación" (p. 18). En efecto, el progreso, que es la "religión de los tiempos modernos", está agotado (p. 19). Peor aún, "la violencia totalitaria del mito progresista es la causa y el efecto de la dominación del mundo social y natural, y de la devastación de estos mundos, cuya [última] expresión es la crisis" (p. 19).

En este libro, en el cual el sociólogo galo desea realizar una "cartografía de la posmodernidad", se trata de constatar, "tras una lenta sedimentación, el reconocimiento y la aceptación de la saturación de una época y, por consiguiente, la emergencia de otra" (p. 22). A ese propósito, conviene precisar que los valores posmodernos no son anti-modernos sino que indican "la emergencia de otro orden de cosas" (p. 23). Precisamente, en el Centro de Estudios sobre lo Actual y lo Cotidiano, Maffesoli y sus colaboradores han desarrollado "la metáfora de la tribu, alternativa a la sociedad cerrada, o (...) unas nociones como la de nomadismo, con sus identificaciones múltiples que se oponen a la asignación a residencia (sexual, ideológica, profesional), característica esencial de los tiempos modernos" (pp. 24- 
25). Sucede lo mismo con el "pacto emocional" que sustituye al "contrato social" (p. 23); sin olvidar el rol del secreto propio a las tribus posmodernas o del "presentismo" específico al hedonismo contemporáneo (p. 25).

Todo ello da sentido al término "societal" que alude al hecho de que, "más allá o por debajo de los diversos poderes (económico, político, [social]), existe una potencia fundadora, la de la centralidad subterránea de cualquier conjunto. Potencia que, al tiempo que es material, es inmaterial, [en la medida en que] es el verdadero cemento que estructura la sociedad" (p. 25). Ese ámbito societal se caracteriza por "la prevalencia de lo cualitativo, la preocupación por la estética [y] un 'corporeismo' invasivo, en la acentuación del instante y en el ideal comunitario, el del intercambio, (...) de los que son llevaderos, en particular, [las nuevas] generaciones" (p. 25). Frente al individualismo, característico de la modernidad, "la tribu, el clan, la comunidad vuelven a estar en el orden del día" (p. 25). El prefijo "co" da muestra de ello. Se trata del sustrato esencial "de una sociedad participativa, colaborativa, mutualista, [en definitiva] comunitaria" (pp.25-26). Gracias a Internet, vía las redes sociales y los foros de discusión, las tribus posmodernas que se crean en torno a una afición compartida, "constituyen un mosaico, la res publica posmoderna" (p. 26).

En ese sentido, el exímoron es "la oscura claridad que constituye la 'unidiversidad' de toda [realidad] humana. El oxímoron (...) es el reconocimiento que hay, a la vez, una multiplicidad de cosas que constituyen lo real" (p. 27). Es cuestión de una convivencia societal que "se nutre de los sueños, de las fantasías [y] de las fantasmagorías de las múltiples tribus que estructuran las sociedades posmodernas" (p. 27). En otros términos, "el oxímoron es la expresión de una lógica "contradictorial"” (p.27). Obedece a una dialogía donde la interacción entre el bien y el mal conduce a "una armonía conflictiva que es propia de la naturaleza humana. No hay solución [ni] resolución. [Es preciso] conformarse con ajustarse [y] acomodarse a lo que hay" (p. 27). En ese sentido, el oxímoron expresa "una retórica societal donde predominan la ambivalencia y la ambigüedad. Esto da cuenta, a la vez, de la riqueza y de la precariedad de una existencia en la cual el riesgo [ocupa] un lugar primordial y donde la aventura es, de manera más o menos consciente, un nuevo ideal de vida" (p. 27).

Así, el oxímoron es "la base continua de la composición instrumental que se esboza en la vida sin cualidad de la cotidianeidad. Perpetúa, de una manera lancinante, el retorno de las tribus, el [auge] del nomadismo, la conjunción del cuerpo y del espíritu, las nuevas formas de generosidad o de solidaridad, todas las cosas que privilegian lo cualitativo [frente] a lo cuantitativo moderno" (p. 28). El oxímoron subraya "la emergencia de éticas plurales, específicas a las tribus posmodernas. El inmoralismo ético es lo que va a caracterizar, cada vez más, la vida en sociedad", sabiendo que la moral es universal mientras que la ética es particular (p. 29). De 
hecho, en la sociedad posmoderna, dominada por el policulturalismo, prevalece la diversidad y las maneras de ser y de vivir se ajustan, en la medida de lo posible, a posteriori (p. 29).

Es evidente, nos dice el autor, que la sociedad moderna basada en el economicismo, el individualismo, el racionalismo, el progresismo y el productivismo está saturada (p. 30). "Numerosos indicios anuncian el próximo final de la época en cuestión. Las fuerzas oscuras del alma colectiva se expresan con una virulencia insospechada. (...) Las diversas formas de generosidad, así como el estallido de los fanatismos religiosos [dan cuenta de ello]" (p. 31). Las revueltas sociales se multiplican y la abstención política indica el final del "ideal democrático". De hecho, las rebeliones actuales de las masas posmodernas revelan la "transgresión de las ideas fundamentales que han constituido los tiempos modernos" (p. 34). Simultáneamente, numerosos indicios revelan la gestación de un "ideal comunitario" (p. 31) al que se adhieren las tribus y las redes sociales en una complementariedad sorprendente (p. 33). Asimismo, la "horizontalización" del mundo es propia de las sociedades posmodernas (p. 32) en las cuales prevalece el "presentismo", ya que toda la energía, tanto individual como colectiva, se concentra con intensidad en el presente (p. 34).

Ante semejante panorama, en el cual los valores posmodernos son cada vez más prevalentes, el autor estima necesario "saber pensarlos", sin temor a las turbulencias (p. 35). Se trata de pensar estas "nuevas formas de existencia con exigencia [y] rigor" (p. 35), lo que implica privilegiar lo cualitativo para poder comprender "el imaginario que sirve de fundamento a cualquier convivencia" (p. 33).

En el segundo capítulo, centrado en la "juvenoïa", Maffesoli muestra que la irrupción de las tribus posmodernas resulta del debilitamiento progresivo de "la creencia en un predominio de la razón soberana. [Debilitamiento], no de la razón, sino de su predominio" (p. 37). Esto va de la mano de la emergencia de la juvenoïa o razón sensible, es decir "una razón completada por los sentidos [y] por el sensualismo" (pp. 37-38). En ese contexto marcado por la unión de lo individual y de lo colectivo, del cuerpo y del alma, el deseo y el placer son considerados como elementos esenciales de cualquier vida en sociedad (p. 38). La juvenoïa expresa "un conocimiento encarnado, hecho de experiencias vividas $[\mathrm{y}]$ de saberes compartidos donde la curiosidad juega un papel esencial" (p. 39). La cibercultura favorece el intercambio y la reversibilidad, lo que fragiliza o, al menos, relativiza "el saber establecido y la arrogancia dogmática que resulta de ello" (p. 39).

La curiosidad implica tomarlo todo en consideración, ya que "cualquier fenómeno humano puede y debe ser intelectualizado. (...) Todo contribuye a un conocimiento pleno de la entereza del ser" (p. 40). Así, el vitalismo juvenil queda de manifiesto en el auge de unos discursos y unas prácticas "lúdicas, festivas, oníricas" 
(p. 40). Lo que era marginal se ha convertido en ineludible, especialmente para la economía (p. 40). Mientras que la modernidad está encarnada por la figura del "adulto serio, racional, productor y reproductor" (p. 41), la posmodernidad está representada por el joven que no quiere crecer y que sigue dependiendo de sus padres (p. 41). Se trata de la "figura emblemática" que expresa el inconsciente colectivo (p. 41). Hoy en día, "el [culto de la juventud] dionisiaco contamina el cuerpo social en su conjunto, todas las clases de edad confundidas" (p. 41). Así, gracias a los cosméticos, cada uno intenta permanecer joven, vestirse, hablar y comportarse como un joven (pp. 4142). Es una de las manifestaciones de "la juvenoïa galopante perceptible en todas las sociedades y en todos los ámbitos" (p. 42). La juvenoïa da cuenta de una preocupación por el "rejuvenecimiento de la relación al ser de las cosas, rejuvenecimiento que pone el acento en una sociabilidad natural e instintiva" (p. 45). La irrupción política de Renzi, Trudeau y Macron ilustra ese fenómeno (p. 42).

A su vez, los proyectos políticos pierden su atractivo porque prevalece el presente. "Al proyecto lejano se opone la visión del presente [y] la intensidad del momento" (p. 43). En ese sentido, la era posmoderna es la del presente y de la inmediatez, la de la experiencia y de lo sensible (pp. 43-44). Asimismo, Maffesoli observa "la intrusión con fuerza, en los diversos discursos sociales, que sean políticos, económicos, periodísticos, universitarios, de las analogías y metáforas" (p. 43).

La juvenoïa recuerda a los poderes instituidos la preeminencia de la política societal (p. 45). En ese sentido, la recrudescencia de lo festivo o, mejor dicho, de la estructura antropológica del imaginario festivo en las sociedades contemporáneas, es ilustrativa del final de un mundo y del advenimiento de uno nuevo (p. 46). Todos los actos, incluso partidistas y sindicales, están marcados "por ese deseo de cantar, gritar, chillar y hacer música conjuntamente" (p. 47). De la misma forma, la política actual no aspira a convencer sino a seducir, "es decir que se trata menos de convencer racionalmente que de hacer vibrar emocionalmente" (p. 50). La teatralidad se impone, de modo que los electores juzgan menos los programas y las propuestas de los responsables políticos, que sus prestaciones mediáticas (p. 51). La vuelta de lo lúdico o de lo festivo en las sociedades posmodernas, nos dice el autor, carece de horizonte particular, dado que se expresa en la multiplicidad de las fiestas y festivales populares (p. 52).

Nada ni nadie escapa a esta juvenoïa invasiva que lo contamina todo ( $\mathrm{p}$. 52). "Lo lúdico y lo festivo de la juvenoïa se encuentran por todas partes (...) para lo mejor y lo peor. Pero, tanto uno como otro son las [dos] caras de una misma realidad" (p. 53). Es también el triunfo de la risa, de la parodia, del pastiche y de otras formas de diversión (p. 53). De hecho, la risa es una forma de resistencia. “Contra la dominación económica, política, simbólica y social, la [risa es], de manera 
desviada, de una singular eficacia" (p. 54). La figura emblemática de Dionysios, "en su incesante juventud, está a la obra en el vitalismo incoercible de las [nuevas] generaciones. Pero, puede igualmente convertirse (...) en el [culto de la juventud] de los perpetuos adolescentes que no quieren crecer y que agotan su energía juvenil en bromas, pastiches y otras parodias infantiles" (p. 55). En ese sentido, el síndrome dionisiaco es el del dinamismo vital. Promueve el saber alegre y está hecho de continuas sorpresas y cuestionamientos (p. 59).

En el tercer capítulo, interesado por la metapolítica, el sociólogo galo considera que la característica principal de la época en gestación es "la saturación o, mejor dicho, la transfiguración de lo político. Sustitución del poder [desde arriba] y vertical por la potencia inmanente y horizontal" (p. 61). La posmodernidad cuestiona el encierre de la política en el Estado-nación que ha conducido Europa a guerras fratricidas. Promueve, al contrario, "el ajuste, en un conjunto federativo, de ciertas naciones locales vinculadas a un territorio, a una cultura y a unos modos de vida compartidos" (p. 65). Ese ideal federativo, basado en un ajuste recíproco de las matrices, orienta el pensamiento y la acción de cada uno, sin exclusiva, lo que explica su gran capacidad integradora de los extranjeros (pp. 65-66).

La actualidad está marcada por las revueltas llevadas a cabo por movimientos societales que expresan "la nostalgia de una 'matrie' que conforta el ideal fundador" (p. 66). Desean "volver a la fuente, al [origen] de la convivencia" (p. 66). A su vez, "la carga mística encuentra de nuevo (...) en la posmodernidad un innegable vigor" (p. 66). De la misma forma, la metapolítica señala un retorno hacia un "humanismo integral" (p. 67) y "las revueltas, rebeliones, concentraciones juveniles y populares, los resultados inesperados de las elecciones (...) son los indicios más pertinentes de esta metapolítica en actos" (p. 67).

En las sociedades posmodernas, la vivencia se impone a la teoría, la experiencia importa más que el sistema, se prioriza lo concreto en detrimento de lo abstracto. Las personas gozan de una sensibilidad que las hace desconfiar del poder que practica una violencia física y simbólica organizada y que privilegia su potencia. Le oponen la convivencia, el hecho de compartir y el intercambio (p. 71). Esto implica que la posmodernidad rechaza "los paraísos ilusorios que se transforman en verdaderos infiernos" (p. 72). Lo que importa es la vida, inmediata, natural" (p. 73). En efecto, para qué sirve luchar por un futuro mejor si la sabiduría consiste en acomodarse a lo que hay. "Por qué creer en una nueva utopía abstracta si es suficiente crear unas pequeñas utopías realizables en la vida cotidiana, la de la convivencia en el día a día" (p. 73).

De la misma forma, tanto el silencio como las protestas violentas "expresan una metapolítica que ya no se satisface de las racionalizaciones abstractas que han constituido la vida política propia a la modernidad" (pp. 73-74). Hoy en día, los 
partidos políticos parecen estar algo desfasados y las organizaciones sindicales solo mantienen a sus afiliados en la medida en que apoyan las acciones espontáneas de sus bases que han dejado de obedecer a las órdenes provenientes de arriba (p. 74). A su vez, las elecciones se han convertido en cada vez más imprevisibles (p. 74). Y, la metapolítica de la ausencia de compromiso y de la abstención es una forma de retirarse voluntariamente y momentáneamente del juego electoral que, a la postre, asegura la potencia y la legitimidad del poder (p. 75).

El cuarto capítulo, dedicado a lo sagrado, subraya el retorno con fuerza "de una apetencia por el misterio, lo desconocido [y] lo indecible" (p. 83). Lo sagrado posmoderno constituye una forma difusa "de un sagrado que no se reduce [a] lo religioso, sino que contamina el conjunto de la sociedad" (p. 84). Alude al reencantamiento que se observa en todas las concentraciones y manifestaciones deportivas, musicales, religiosas e incluso políticas. Pero, se expresa, también, en las nuevas formas de solidaridad o de generosidad que reencuentran un innegable vigor. Las palabras "voluntariado", "caridad", "servicio", "ayuda mutua" o "colaboración" dan cuenta de ello. Todo esto expresa el reencantamiento a la obra (pp. 84-85). "Sin olvidar, evidentemente, el desarrollo de los movimientos sectarios y de los diversos fanatismos religiosos" (p. 85).

Las personas participan masivamente en las peregrinaciones religiosas, se apropian una parte de sagrado en las fiestas tradicionales, vibran en los grandes festivales musicales y apoyan con fervor sus equipos de futbol. En todos estos casos, "se trata de vibraciones religiosas" (p. 86). Es cuestión de compartir pasiones y emociones, relacionando a la gente. En ese sentido, ese "relacionismo" es la esencia misma del hecho religioso (pp. 86-87). "El materialismo espiritual o el "corporeismo" místico de la que hacen gala las [nuevas] generaciones constituyen sus mejores ilustraciones" (p. 88).

El olvido de lo sagrado, nos dice el autor, es la causa y el efecto de la miseria humana, "olvido que conforta el desamparo galopante y la soledad moral de la que se empiezan a medir los efectos (...) preocupantes" (p. 94). A ese respecto, paradójicamente, "el desarrollo del economicismo moderno proviene (...) de una cierta concepción de lo sagrado" (p. 94). No en vano, el economicismo hace todo lo posible para ocultar los orígenes religiosos de la economía (p. 96). Según Maffesoli, el rechazo de los orígenes espirituales está en el origen de la crisis posmoderna. Lo cualitativo vuelve con fuerza y se produce una "reafirmación de las diferencias, particularismos [y] especificidades" (p. 96).

La interacción entre el comercio de los bienes, las ideas y los sentimientos, "que subraya la complejidad de toda existencia humana y de toda vida colectiva, [confiere] de nuevo una fuerza innegable a la dimensión sagrada de cualquier vida en sociedad" (p. 97). En ese sentido, las sociedades más armoniosas son aquellas 
que han permitido la expresión de lo sagrado. De hecho, "la aceptación del exceso [y] su ritualización permiten una purificación del cuerpo social. Es la catarsis [que consiste en] una descarga emocional que suscita un alivio para el alma colectivo e incluso su elevación" (p. 97). En efecto, el racionalismo moderno ha querido ocultar cualquier forma de sagrado. Este, tal el retorno de lo reprimido, "resurge en unas formas paroxísticas y totalmente descontrolables" (p. 99). En definitiva, "lo que está en juego en lo sagrado, correlativo de un evidente reencantamiento del mundo, es el deseo, más o menos consciente, de romper las barreras establecidas, de una manera intangible, entre la razón y la imaginación, el cuerpo y el espíritu, la naturaleza y la cultura" (p. 107).

En el quinto capítulo, titulado "Nosotros", Maffesoli atisba que "asistimos a la elaboración, como todo lo que está al estado naciente, de manera dificultosa, de un ideal comunitario" (p. 109). El tríptico característico de la modernidad, es decir individualismo, progresismo y racionalismo, es sustituido en la sociedad posmoderna por el tríptico "personalismo tribal, presentismo y emocionalismo" (p. 109). En efecto, frente a la individualización de la era moderna, surge la individuación de la época posmoderna que consiste en la realización de un tipo específico o universal. Mientras que la primera es la reducción del Uno a lo individual, la segunda es "la expresión de ese individuo en un conjunto más amplio: el de la comunidad en la que se sitúa y de la naturaleza en la que está" (p. 110). En otros términos, asistimos a la metamorfosis del individuo autónomo en una persona heterónoma (p. 110).

Estamos en la época de las tribus, del ideal comunitario, del retorno de los clanes (p.110). Se trata de una vuelta a los orígenes, al intercambio y a la ayuda mutua en el seno de la comunidad que se ubica en un territorio determinado (pp. 110-111). En ese contexto, el individuo comparte un mundo común que va de la mano de un sentido común. Este, "más allá de las diversas recuperaciones políticas contemporáneas, subraya la prevalencia de un sentido compartido" (p. 112). De la misma forma, el hecho de compartir e intercambiar es esencial. Como to ha subrayado Marcel Mauss (2012), "dar, recibir y devolver (...) son el fundamento de toda sociedad" (p. 112). A su vez, se observa "una propensión a una mayor tolerancia en la vida social" (p. 113). De hecho, paralelamente a cierta tendencia a encerrarse en sus fronteras y a rechazar al extranjero, se constata "una apuesta por la alteridad y [el respeto de] la diferencia" (p. 113). Está especialmente presente entre las nuevas generaciones para las cuales "los intercambios (...), los viajes [y] el turismo son una realidad innegable" (p. 113).

De manera general, "el nomadismo está al orden del día" (p. 113). Según el autor, el nomadismo debe entenderse en un sentido amplio. Más allá de la mera movilidad, es todo aquello que permite "salir de una identidad individual, a fin de participar en estas identificaciones comunitarias" (p. 113). 
Esto va de la mano del resurgimiento de las comunidades de destino que comparten un espacio común y son la causa y el efecto de una nueva temporalidad de la convivencia: "la del eterno presente" (p. 115). Estas comunidades se enfrentan a lo trágico de la existencia que expresa "unos tipos e incluso unos arquetipos" que solo valen en la medida en que un individuo pertenece a una comunidad. Además, no hay solución o resolución posible” (p. 115). Por lo cual, es preciso componer con él (p. 115). La comunidad "conforta y reconforta" (p. 115). Es un sistema de interacciones donde, gracias a la intersubjetividad y la cibercultura, las solidaridades, las ayudas mutuas y el hecho de compartir se expresan (p. 115). En esta óptica, las personas no existen por sí mismas, sino porque están relacionadas en lugares concretos. Las comidas en la calle, las reuniones de vecinos, las concentraciones espontáneas suscitadas por las redes sociales o el activismo en Internet son expresiones de la comunidad que constituye "el residuo irrefragable de la convivencia antropológica" (p. 117).

La reviviscencia de lo emocional, es decir de los sentimientos básicos, es lo que "conforta, en profundidad, el vínculo societal" (p. 118). Es lo que funda toda verdadera comunidad (p. 118). En ese sentido, el ideal comunitario, como manifestación de un "Nosotros" vivido a diario, descansa en esa razón sensible que asocia la razón y los sentidos, la racionalidad y el sentido común (p. 118). "La vuelta del 'nosotros', el del tiempo de los tabúes, es (...) la expresión más nítida del cambio de paradigma [en curso]" (p. 119). Según Maffesoli, "la influencia difusa de la comunidad se cristaliza (...) en un humanismo integral, donde es la entereza de la persona la que se realiza en la comunidad" (p. 119). Tanto el humanismo integral como el transhumanismo recuerdan dos aspectos esenciales que constituyen el ser humano: "su naturaleza y su condición. La naturaleza hecha de potencia, es decir de potencialidades. [La] condición dibuja unos límites que conviene respetar" (p. 119).

La comunidad es un vínculo singular que no se puede olvidar impunemente (p. 119). "Dado que la condición humana, solo puede vivir en comunidad, se vive por abajo, a partir de lo que, en el sentido [pleno] de la palabra, asegura, es decir da seguridad y [fundamento]" (p. 119). Se trata de un acondicionamiento vivido tribalmente, ya que se produce un "ajuste común a un territorio dado, que permite comprender la importancia que reviste, hoy en día, la empatía" (p. 120). Así, los responsables políticos hacen muestra, públicamente, de sus pasiones, emociones y afectos. Lloran y se ríen en público para mostrar que ellos también forman parte de la comunidad y, por lo tanto, "participan a sus alegrías y penas" (p. 120). En ese sentido, el hecho de llorar de placer o de tristeza conforta el ethos colectivo. Es lo que hace la fuerza de la empatía (p. 120).

A su vez, la confianza y la fe compartidas constituyen el sustrato de toda vida en sociedad (p. 121). En efecto, hoy en día, la reviviscencia del ideal comunitario es 
"un romanticismo que (...) es vivido en el día a día" (p. 125). La mejor prueba de ello es que, actualmente, "el pueblo encuentra de nuevo su alma colectiva, es decir su potencia", que expresa en las agrupaciones, las concentraciones multitudinarias, las congregaciones, las tribus y los clanes (p. 126).

En el sexto capítulo, centrado en la iniciación, el sociólogo galo subraya que "la vivencia experiencial compartida, que es lo propio del ideal comunitario, anima, en profundidad, la verdadera vida social" (p. 129). En ese sentido, la vida cotidiana y ordinaria constituye el sustrato de toda existencia (p. 129). La valorización de la experiencia es el indicio más claro del cambio de paradigma. "Ese cambio renueva, fundamentalmente, el proceso de transmisión" (p. 130). Por lo cual, la socialización de la energía juvenil y su canalización sin empobrecerla demasiado pasan por la educación y la iniciación, sabiendo que "lo esencial en la educación es la doctrina inculcada", mientras que "el punto nodal de la iniciación consiste en acompañar y en hacer resaltar el tesoro que es cada uno" (p.130). Dicho de otro modo, "la educación consiste en integrar, de manera mecánica, cada individuo en ese conjunto unificado que es la sociedad. Para ello, la 'ley del padre' se impone, verticalmente, a cada uno (...). La iniciación, de su parte, es un proceso más dúctil que asocia, orgánicamente, cada persona a estas pequeñas entidades que se nombran comunidades (...), tribus o clanes. Por lo cual, es la 'ley de los hermanos' o la 'ley de los iguales' que prevalece” (p. 130).

La horizontalidad es su característica esencial (p.130). En ese sentido, el paso de la modernidad a la posmodernidad es ilustrado por el "deslizamiento de lo vertical hacia lo horizontal" (p. 131) que puede observarse empíricamente en todos los ámbitos de la vida social (p. 131).

La iniciación es lo que da nacimiento. Es lo que "permite, cada día, acceder al nacimiento del mundo y de las cosas que lo componen. Así, la transmisión, la socialización es menos la imposición de un saber establecido que el acompañamiento hacia un conocimiento [preciso]. (...) Se trata, por lo tanto, de un proceso de maduración progresiva" (p. 133). Esto significa que la iniciación comunitaria es "una elevación (...) que va más allá y por debajo de los intereses individuales y de las estrechas pasiones particulares, hace participar al bien común o al interés común” (p. 134). Ese ideal comunitario "da todo su sentido, es decir su significado, a una vida plena y entera" (p. 134).

De hecho, "en el seno de una comunidad, (...) se puede ser solitario pero no estar aislado" (pp.134-135), ya que, en la sociedad posmoderna, "la persona plural, [gracias a] las redes sociales, expresa sus deseos, sus fantasmas y sus fantasías" (p. 135). De esta manera, desde su domicilio, "está unida a las tribus cuyos gustos comparte" (p. 135). Por lo cual, la posmodernidad se caracteriza por la "sinergia de lo arcaico y del desarrollo tecnológico" (p. 135) o, dicho de otra forma, de las tribus y de Internet (p. 136). Así, “en la multiplicidad y la 
polivalencia de los foros de discusión", se instaura un saber cooperativo (p. 136). "Es esa la horizontalidad de la "ley de los hermanos o de los iguales"” (p. 136). Las redes sociales ponen de manifiesto "una innegable vitalidad que expresa una nueva manera de convivir" (p. 136).

La socialización contemporánea reinvierte, con la ayuda de la tecnología, "un arquetipo que es la iniciación. Las leyes y las reglas dejan de estar impuestas desde arriba, verticalmente, para ser vividas experiencialmente, "con la ayuda de los demás" (p. 137). "Los hábitos y las costumbres que (...) creíamos superadas y olvidadas, encuentran un nuevo vigor" (p. 138). En ese sentido, la armonía solo puede ser conflictiva. Esta tensión, convertida en una coacción, permite, a largo plazo, la pervivencia (p.139). "Es la pervivencia de las tensiones, su utilización inteligente, que permite que la convivencia no sea una [mera indiferencia], sino una vida [intensa], en la cual las asperidades, las limitaciones, las coacciones de todo tipo contribuyen a un relacionismo en el cual las fricciones concurren a la intensidad del conjunto" (p. 140).

Las pruebas iniciáticas tienen como fin integrar al novato, al principiante, a la comunidad haciéndole interiorizar los valores del ideal comunitario (p. 140). "La iniciación, a través de unas pruebas, recuerda (...) la dura realidad de la condición humana" (p.141). El ser humano necesita ese rigor para poder crecer y desarrollarse. Es preciso, a largo plazo, pulirse para acceder a un nivel superior y participar en la comunidad del que forma parte. Pero, esta participación no se hace sin dificultades (p. 141). La iniciación implica "el conocimiento [a través de] las pruebas de la vida, las pruebas simbólicas que, a fin de cuentas, favorecen una real elevación” (p. 142). La iniciación hace abstracción del sistema y se interesa por "la concreción de las cosas, su dureza para obtener un mayor ser. Es lo que puede calificarse de 'vivencia experiencial"” (p. 142). En definitiva, "con la ayuda de los demás, y a través de un conocimiento ordinario, [se trata de] aceptar la lección de los acontecimientos, es decir del destino que no se puede (...) controlar en totalidad" (p. 142).

En el séptimo capítulo, que se interesa por la tradición, el autor estima que asistimos a un retorno de la tradición. De hecho, se observa "la intensidad del sentimiento de pertenencia tribal [y] la reviviscencia del sentimiento de pertenencia a una corporeidad individual y colectiva" (p. 144). En esta óptica, "la renacimiento posmoderno implica iniciación [y] restitución, es decir aceptación de la herencia" (p. 146). "El éxito de las festividades históricas, que recuerdan las horas gloriosas de la nación, de un lugar relevante [y] de una batalla, está ahí para demostrar todo lo que debemos a la herencia de tiempos pasados" (p. 146). En ese sentido, "la tradición recuerda que, más allá y por debajo de la abstracción moderna, no existe un sociedad sin raíces profundas" (p. 148). Incluso la globalización "conforta el rol de la tradición y de los usos y costumbres” (p. 148). La tradición, nos dice 
Maffesoli, constituye el secreto escondido donde, "según las épocas, se va a buscar tal o cual característica de la vida en sociedad" (p.150).

La unicidad, que es totalmente empírica, escoge en la tradición "otra manera de pensar y, por consiguiente, de actuar, privilegiando la diversidad, el pluralismo de los valores, el tiempo que asegura la cohesión de ese conjunto" (p. 150). En ese sentido, "la pluralidad y su enraizamiento tradicional" van de la mano (p. 152). La tradición, recordando la entereza de la condición humana, ha mezclado lo espiritual y lo material (p. 155). Asimismo, la tradición es, a la vez, "lo que es inicial y, por ese mismo hecho, lo que permite y asegura una verdadera autoridad, es decir (...) lo que hace crecer" (p. 152), dado que las raíces permiten el crecimiento (p. 158). De la misma forma, "las ideas tradicionales son como unas piedras que, de generación en generación, se transmiten en las familias y de las que [solo] se cambian la disposición (...) según la moda de la época. Pero, lo esencial, [es decir] la piedra, es intangible” (pp. 156-157). Esto significa que la condición humana no puede escapar de la tradición (p. 159).

En el octavo capítulo, dedicado al naturalismo, Maffesoli constata que "el retorno del naturalismo [y] el retorno al naturalismo, es, ciertamente, lo que resume mejor la lenta pero inexorable emergencia de los valores posmodernos" ( $\mathrm{p}$. 164). Traduce la apetencia hacia ese mundo (p. 164). El ser humano, como animal humano, es también un animal. "Con las especificidades que eso tiene: importancia de los sentidos, realidad de la agresividad y aspectos no desdeñables de los afectos. Lo natural y lo comunitario superan e integran cada individuo como tal (p. 166). Al estar involucrado en un ambiente emocional, "el elemento importante es menos la explicación del mundo que la participación en ese mismo mundo" (p. 166). La política no escapa a ese ambiente emocional. La moda de los selfies da cuenta de ello. A través de ella, "tal personalidad política participa a las emociones colectivas y, de ese modo, hace participar los diversos protagonistas a la aura de la que es llevadera" (p. 167).

Con el naturalismo, "la vida y lo común se conjugan y sirven de estuche, que reúne según una gradación variable [en función] de los lugares, lo vegetal, lo animal y lo humano, [a saber] el conjunto de los seres vivos" (p. 168). Existe, actualmente, un retorno a la naturaleza y a la tierra madre (p. 172). Las formas sociales efímeras, como las instituciones, "son tributarias de la matriz natural" en la cual se halla la fundamentación de la convivencia (pp. 172-173). Y, frente al modernismo destructor que aspira a dominar la naturaleza, emerge un humanismo integral que pretende crear de nuevo un vínculo armonioso con la naturaleza (p. 175).

En el apartado de conclusiones, titulado "Epinoïa", el sociólogo galo observa que, dado que las modalidades de convivencia están en crisis, el conocimiento que la sociedad tiene de sí misma afecta igualmente a su transformación (p. 177). Emerge un pensamiento desde la base, que, en su propia incertidumbre, está abierta a la intensidad de lo que acontece (p. 177). La epinoïa es "un camino de pensamiento 
haciéndose al andar. No a través de sistemas preestablecidos, sino elaborándose a posteriori, en función y a partir de la vida de todos los demás" (p. 178). Trata de describir lo que existe en lugar de querer proclamar lo que debería ser (p. 178), y la eponoïa consiste en saber discernir lo sustancial de lo accesorio (p. 179). Permite pensar la posmodernidad, que se caracteriza por la figura emblemática de Dionysos, “el tiempo de las tribus y la época del nomadismo" (pp. 190-191).

Al término de la lectura de Être postmoderne, es obvio reconocer la originalidad del pensamiento de Michel Maffesoli (centrado en el análisis de la posmodernidad que se funda en el tribalismo, el nomadismo y el hedonismo), así como la creatividad conceptual de la que hace gala, lo que permite renovar la perspectiva teórica prevalente en las ciencias humanas y sociales tanto en Europa como en Estados Unidos. Parte, para ello, de su amplia cultura filosófica, su profundo conocimiento del griego y su interés por la literatura, para ofrecer una amplia genealogía donde no duda en recordar la etimología y el significado de las nociones, ejerciendo de filólogo. Lo hace utilizando un estilo fluido y elegante y usando un vocabulario rico y variado. No en vano, de cara a matizar la valoración positiva que merece esta obra, el autor tiene cierta propensión a abusar de las generalidades y le cuesta, a veces, ir a lo esencial. Más fundamentalmente, su voluntad de cuestionar el modernismo y el intelectualismo, lo conducen a sobrevalorar el sentido común y a idealizar la tradición, aunque entienda esa noción en un sentido novedoso.

Pero, más allá de estas críticas, la lectura de uno de los pensadores contemporáneos más creativos de la actualidad se antoja ineludible para mejorar nuestra comprensión de la posmodernidad.

\section{BIBLIOGRAFÎA}

Maffesoli, M. (1979): La conquête du présent. Pour une sociologie de la vie quotidienne. París: PUF.

Maffesoli, M. (1985): La connaissance ordinaire. Précis de sociologie compréhensive. París: Librairie des Méridiens.

Maffesoli, M. (1988): Le temps des tribus. París: Le Livre de Poche.

Maffesoli, M. (1992): La transfiguration du politique. París: La Table Ronde.

Maffesoli, M. (1997): Du nomadisme. Vagabondages initiatiques. París: Le Livre de Poche.

Maffesoli, M. (2004): Le rythme de vie. Variation sur l'imaginaire post-moderne. París: Table Ronde.

Mauss, M. (2012): Essai sur le don. París: PUF. 